\title{
THE ROLE OF SERVICES BASED ON THE SHARING ECONOMY MODEL IN THE SMART CITY 3.0 CONCEPT
}

\author{
JACEK RUDEWICZ \\ University of Szczecin, Faculty of Geosciences, POLAND \\ e-mail: jacek.rudewicz@usz.edu.pl
}

\begin{tabular}{l|l} 
RECEIVED & 10 December 2018 \\
ACCEPTED & 28 December 2018 \\
JEL & \\
CLASSIFICATION & 014,035
\end{tabular}

KEYWORDS social enterprise, social entrepreneurship, social innovation, service sector, technological adoption, technological choice

ABSTRACT This article was created in order to identify and highlight emerging new development opportunities for services based on new technologies and solutions falling into the category of WEB 2.0 and socialization of services through internet tools and social media. In the article will be presented the classification of these services and discussed their role in urban development, as well as in the implementation of the smart city concept. In text will be also outlined the problem facing the city authorities and legislators which are services in the shared economy. They are a problem because, due to their nature and the channels of market communication that they use, they are out of full administrative control. These services also compete with entrepreneurs operating in the service industry in traditional organizational structures. The aim of the article will be implemented through a review of literature and internet reports - due to the specificity of the subject, the most current source of information. In this review article, the content has been supplemented by the author's own observations.

\section{Introduction}

An introduction to the problems raised in the article requires theoretical support and definition issues. The first step is to explain what is Smart City's vision of the city. Another action attempts to explain the essence of the sharing economy. Smart cities and the sharing economy consist of various elements are complex concepts with fuzzy boundaries. Both concepts described in the article do not have commonly agreed definitions and are often defined 
by a list of features, not by a comprehensive concise definition. This is due to the difficulty of describing the modern world, especially the relatively new socio-economic phenomenon. A smart city is a concept strictly related to cities, while the sharing economy has a wider range. However, its natural environment and incubation site is the city, the metropolis and creative and aware residents.

\section{Smart City generations}

There are a lot of definitions of smart city in literature, people interested in the subjectwill find studies classifying and systemizing definitions in many articles, for example in the article titled "Unified Definition of a Smart City" (Ramaprasad, Sánchez-Ortiz, Syn, 2017, pp. 13-14), or an article entitled "Smart cities: definitions, dimensions, and performance" (Albino, Berardi, Dangelico, 2018, pp. 3-21). In short, a city can be considered as "smart" when its investment in human and social capital and in communications infrastructure actively promote sustainable economic development and a high quality of life, including the wise management of natural resources through participatory government. The concepts of the smart city do not exclude the assumptions of other urban concepts (more Mierzejewska, 2015, pp. 8-10), it differs only in the greater involvement of technology in order to create cities described by other concepts. For this reason, it is a more operational concept. The increase in the popularity of this concept correlates with the emergence and popularization of LTE and $5 \mathrm{G}$ connectivity and mobile devices. Urban residents will democratically decide on the degree of use of technology in the city's life. Technology may raise some resistance, for example, by issues related to personal data and surveillance. Technology is becoming widespread and plays an increasingly important role in everyday life, culture and economy, replacing the "analogue world". A well-known figure for people interested in the topic of urban studies Boyd Cohen presented three generations of implementation of the smart city idea in cities (Cohen, 2015).

\section{Smart Cities 1.0 (Technology Driven)}

This generation is characterized by the fact that the ICT technologies companies encourage the adaptation of their technologies by city authorities in order to achieve greater efficiency in the management of urban organisms. However, cities are often not prepared to implement these technologies and to properly assess how these technologies can affect the quality of life of their citizens. This generation of smart city is heavily criticized for its leading role ICT corporations in the process of creating smart cities. Corporations that see only a fragmentarily complex system which is a city.

\section{Smart Cities 2.0 (City Led)}

The city authorities play an overriding role in the implementation of the vision of a smart city, focusing on technological innovations as tools to improve the quality of life of the inhabitants. Cities of the second generation of Smart Cities are characterized by a large number of urban programs and projects that serve the implementation of modern technologies in different areas of the city's life. The literature is presented an example of Barcelona, where are about 100 city projects related to the smart city (Gavaldà, Ribera, 2012).

\section{Smart Cities 3.0 (Citizen Co-Creation)}

This is the latest generation of smart cities that has recently appeared. It is characterized by the fact that residents take a key role in the development of cities. In the Third Generation Smart Cities, residents start to co- 
create their cities. Examples of such cities are: Vienna, Vancouver and also Colombian Medellín, which shows that such cities do not have to be located in highly developed countries. What is important, in Smart Cities 3.0 projects of social character, equality, social inclusion, cheap construction, etc. play a significant role. An appropriate place in this concept has the sharing economy (collaborative consumption). Table 1 presents the basic functional areas of intelligent solutions for cities. As we can see, they concern many spheres of the functioning of cities, from typically technical and engineering, that is, the sensor level in the roadway to the level of urban communities.

Table 1. Basic functional areas of Smart City considerations according to Vienna University of technology - characteristics and factors of a smart city

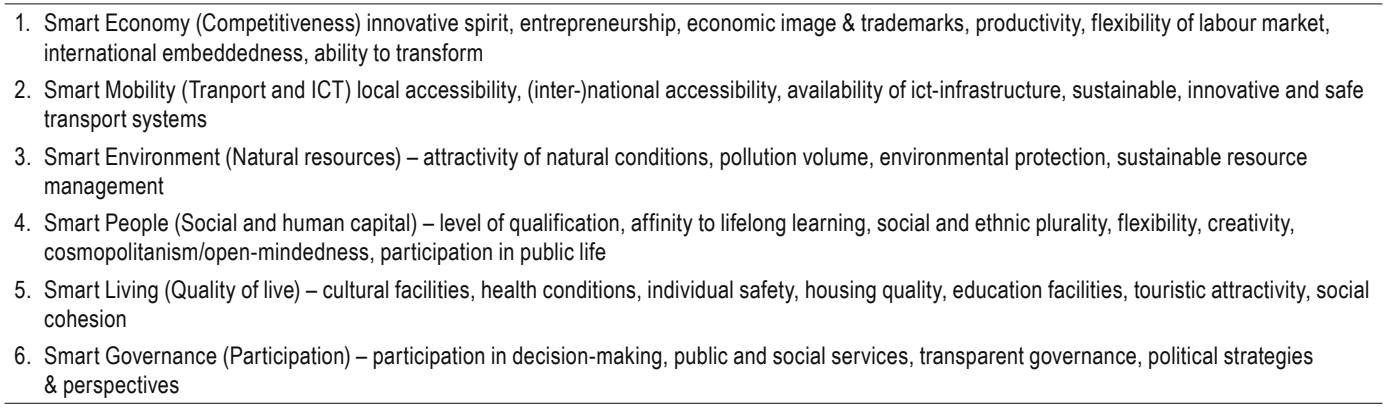

Source: Smart cities Ranking... (2007), pp. 11-12.

Remaining on the definitional issues and merits of the article, the explanation requires how are defined services based on internet communication platforms and mobile applications and social open supervision over the quality of these services. Well, these services fall into the category of sharing economy. Other names referring to this phenomenon found in the literature in English are: "collaborative consumption", "collaborative economy", "on-demand economy", "peer-to-peer economy", "zero-marginal cost economy", "crowd-based capitalism" (Selloni, 2017, pp. 15-19).

\section{Shared economy - understand the phenomenon}

In 2010, Rachel Botsman and Roo Rogers published the first book on the sharing economy entitled "What's Mine Is Yours - the rise of collaborative consumption" (Botsman, Rogers, 2010). The authors defined the sharing economy as a traditional sharing, bartering, lending, trading, renting, gifting, and swapping, redefined through technology and peer communities to be made by using technology and the existence of online communities. In the article from 2017 on "Putting the sharing economy into perspective" Koen Frenken and Juliet Schor defined the sharing economy as "consumers granting each other temporary access to under-utilized physical assets ("idle capacity"), possibly for money". The authors identify three characteristic shared economy features. These are: interaction between consumers (C2C), temporary access and use of physical goods (Frenker, Schor, 2017, pp. 3-10). The sharing economy is not a completely new phenomenon. Traditionally, sharing has always been an alternative to a capitalistic, profit-oriented economy. Informal sharing and collaboration networks exist in different societies. The novelty of the present cooperation economy is based on the use of information technology as a channel for the exchange of market information and the implementation of the sharing process. Pablo Munoz and Boyd Cohen, 
using the work of McLaren and Agyeman (2015) and Martin et al. (Martin, Upham, Budd, 2015) and Chasea (2015), define the economy of cooperation as: "a socio-economic system enabling an intermediated set of exchanges of goods and services between individuals and organizations which aim to increase efficiency and optimization of under-utilized resources in society". According to this definition, the sharing economy and services that are implemented within its framework correspond to the paradigm of sustainable development. It is possible to re-use many goods, redistribute them, extend the life cycle of the product. The sharing economy and its organizational and distribution model give a chance to many people who, despite their competences, have a difficult start in traditional (service) business involving the regulations and supervision of the state. Sharing economy manages part of the activity of these people, which belonged to the gray zone. These are, for example, immigrants, students, pensioners, unemployed people. An essential issue in considering the sharing economy is the linking of sharing with commercial activities. The largest global corporations operating on the basis of platforms (online marketplaces) such as websites and applications are, for example, Airbnb and Uber. These are commercial enterprises, focused on profit. Despite this, they meet the criteria for belonging to shared economy. Rachel Botsman (2015) believes that shared economy is a concept often wrongly referred to business solutions based on effective matching of demand and supply, which, however, do not take into account either sharing or cooperation. Overuse the category of belonging to the sharing economy sector, the mobile application, the efficient algorithm and the payment system are not enough. Botsman proposes five conditions that companies must meet in order to be considered as belonging to the sharing economy.

1. The core business idea involves unlocking the value of unused or under-utilized assets ("idling capacity") whether it's for monetary or non-monetary benefits.

2. The company should have a clear values-driven mission and be built on meaningful principles including transparency, humanness, and authenticity that inform short and long-term strategic decisions.

3. The providers on the supply-side should be valued, respected, and empowered and the companies committed to making the lives of these providers economically and socially better.

4. The customers on the demand side of the platforms should benefit from the ability to get goods and services in more efficient ways that mean they pay for access instead of ownership.

5. The business should be built on distributed marketplaces or decentralized networks that create a sense of belonging, collective accountability and mutual benefit through the community they build.

At this point, it is worth refining the attempt to understand the essence of the sharing economy for the classification of services that fall within its scope. The Department of Economy and Statistics of the United States (U.S. Department..., 2016) has identified over 20 service areas in which the assumptions of the sharing economy are present. Lisa Gansky (2010) in the book entitled "The Mesh" has identified 25 categories of this type of service and over 9,700 network companies located in more than 1,630 cities in more than 130 countries. The most popular attempt to classify is the honeycomb of collaborative economy (sharing economy) created by Jeremiah Owyang. On its basis, was created a table presenting 16 categories and 44 subcategories - service functions supported by enterprises from the branch of sharing economy.

The problem is the attempt to regulate economic activity that is part of the broad framework of the sharing economy. Paradoxically, this area of the economy uses the digital communication platform to effectively use free resources in an innovative and creative way. On the other hand, the economy of cooperation creates new fields of conflict and competition for similar economic activities with a traditional way of organization and evolution on the market. For example, the service offered by the Uber platform involving the use of a private car to transport 
Table 2. Categories and sub-services of shared economy services

\begin{tabular}{|c|c|}
\hline Category & Sub-category \\
\hline Analytics and reputation & $\begin{array}{l}\text { Driver services Identity and reputation } \\
\text { Renter services }\end{array}$ \\
\hline Corporations \& organizations & $\begin{array}{l}\text { Employee services Platforms } \\
\text { Supply chain }\end{array}$ \\
\hline Food & Food delivery Shared food Shared food prep \\
\hline Goods & Loaner products Maker movement Pre-owned goods \\
\hline Health & Peer to peer Care services \\
\hline Learning & $\begin{array}{l}\text { Book sharing } \\
\text { Instructor-Led } \\
\text { Peer-to-peer }\end{array}$ \\
\hline Logistics & $\begin{array}{l}\text { Local delivery } \\
\text { Shipping } \\
\text { Storage }\end{array}$ \\
\hline Mobility services & $\begin{array}{l}\text { Ride hailing } \\
\text { Bicycles Parking Support Valet services }\end{array}$ \\
\hline Money & $\begin{array}{l}\text { Crowdfunding } \\
\text { Cryptocurrencies } \\
\text { Money lending }\end{array}$ \\
\hline Municipal & City Sponsored Bikes Platforms \\
\hline Services & $\begin{array}{l}\text { Business } \\
\text { Personal }\end{array}$ \\
\hline Space & $\begin{array}{l}\text { Personal space } \\
\text { Work space }\end{array}$ \\
\hline Utilities & $\begin{array}{l}\text { Energy } \\
\text { Telecommunications }\end{array}$ \\
\hline Vehicle sharing & $\begin{array}{l}\text { Loaner boats } \\
\text { Loaner vehicles }\end{array}$ \\
\hline Wellness \& beauty & $\begin{array}{l}\text { Beauty } \\
\text { Wellness }\end{array}$ \\
\hline Worker support & Insurance Renter services Resources \\
\hline
\end{tabular}

Source: adapted from Owyang (2014); Ganapatia, Reddickb (2018).

of people through the use of reservations via smartphones causes protests by taxi drivers and taxi corporations. The conflict takes place in the field of the ethos of the profession and the costs of taxi operations and price competition. In many places around the world, governments and courts have intervened in similar disputes limiting or barring economic activity in the model of sharing economy. An example of this is the draft act on road transport in Poland. This problem is also visible in the case of urban space, city centers and attractive locations are successively filled with premises in the offer of Airbnb and similar companies, affecting local real-estate markets and displacing residents from the attractive tourist areas of cities. At the same time, traditional hotel and hospitality activity faces the challenge of competition - often untaxed. An example is the Airbnb corporation, whose capitalization is catching up with the Hilton and Marriott hotel chains. Establishing sharing economy and the differences between market exchange and sharing in a pure ideological form assume the marginal importance of commercial business solutions and profit-making in this type of business. Shared economy is, however, subject to a market game, and the value of companies initially starting as a start-up, e.g. Uber or Airbnb is growing. In the last decade, the value of entities operating in the area of cooperation economics grew exponentially. The PricewaterhouseCoopers in the report 
"The sharing economy" (PWC, 2015) estimates that from USD 15 billion in 2014, the value of these entities will increase to USD 335 billion in 2025. Thus, we are dealing with a dynamically developing phenomenon on a global scale. There are many statistics confirming the above claims about the rapid increase in market share and the value of assets of enterprises associated with sharing collaborative economy. An example is the chart - Figure 1 presenting the increase in the number of guests using Airbnb services in London. Similar charts about the almost exponential growth are published by other cities from around the world.

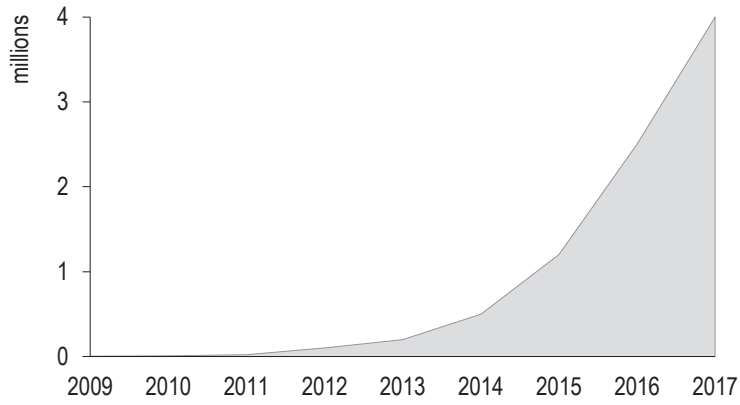

Figure 1. Cumulative guest arrivals at Airbnb listings in London area

Source: Airbnb (2017).

\section{The role Sharing Economy in the implementation of the Smart City concept}

Returning to the concept of the smart city presented above, the postulate contained in the description of the Smart City 3.0 generation becomes true. The postulate concerning social inclusion, in this case in economic activity, indirectly strengthening social interactions and more efficient use of resources and goods. Sharing economy contributes to equalizing opportunities, giving access to unused resources at a fraction of the cost to those who cannot or not wants to buy new products and a chance for additional income for those who already have such unused resources (things, space, capital, equipment, free time). The sharing economy is seen as an instrument in dealing with problems such as over-consumption and income inequality. The sharing-based business has evolved from simple loan initiatives to complex platforms and networks connecting individuals and enterprises to collaborate and collectively use existing or new labor, land and capital resources. The genesis of this economic phenomenon is a combination of several factors, in the literature it is indicated that it was the global economic crisis of 2008, the emergence of high-speed internet, change of the generation of network communication on WEB 2.0 (social media), increased interest in environmental and sustainable development issues and to a certain extent the renaissance of thinking in terms of community in cities. The sharing economy due to its special features is combined with the concept of Smart City. Thanks to the creation of a friendly environment for the development and diffusion of enterprises sharing economy, cites can achieve the goals of a Smart City. Cities are a natural sharing environment, a social territorial system (Chojnicki, 1989). Internet platforms work best in the local community and short distances. The complementarity of smart cities and the sharing economy depends on the attitude of city 
authorities to innovation. It should also be noted that sharing can also indirectly contribute to the city's economic success. Appropriate policy towards bottom-up phenomena and activities in the area of shared economy brings benefits to residents, but may limit potential tax inflows if this activity was undertaken in a traditional way. An element that can be shared in the future is the production of renewable energy. City residents as prosumers producing energy for themselves and reselling it to dispersed energy networks. Crowdfounding is a strong growing area of activity - a way to finance projects, initiatives and start-ups, and help when it is necessary. For the smart cities, there are goals to reduce resource consumption, savings, social inclusion, equalizing opportunities, and stimulating entrepreneurship. Smart cities are not a static concept. This concept will also be remodeled, because we are not able to determine the path of technological progress and social implications that it will cause. Jeremiah Owyang made an attempt at such a slightly futuristic look. In the five-digit concept of the digital world of Jeremiah Owyang (2018), the sharing economy occupies the third position. The era of the Internet is the exchange of information in a one-sided way, in the 90 s, it was called the dot-com era, which was ended by a deep economic crisis. The next era is social media and WEB 2.0, in which the users became the creators themselves, and marketers got tools to directly reach to customers. We are currently experiencing the third era - the development of the sharing economy, people have been given the opportunity to get what they need from themselves. The next era according to this author will be the era of the autonomous world. Currently, these technical solutions are in the testing phase. The third era may threaten some of the economic activities of the cooperation economy, because social support and sharing will be replaced by autonomous solutions, e.g. autonomous cars, artificial intelligence support for business and advisory services. The fifth era is the era of modern prosperity, in which the bodies and minds of people and their surroundings will be supported by advanced technology. Owyang thoughts, if they prove to be true in their part regarding the future, will mainly concern cities because we are observing globally upward trend in the number of their inhabitants.

\section{Conclusions}

The sharing economy and related services have a significant share in building cities in line with the smart city concept, in which technology is only a tool supporting the implementation of human needs, including the needs of the higher positions of Maslow pyramid. One might risk the thesis that in some way social services and activities will be substitutable and competitive for strictly technical solutions. One can imagine that instead of the sensor in the urban space, for example, the inhabitants themselves will be informed about the threat of smog, through a special application with geolocation (this is already happening in Poland). Modern technologies, ICT infrastructure and its services as well as communication platforms are complementary products for cooperation economics. The scope of cooperation economy will depend on traditional human resources and social capital in the city. This capital is stimulated by social media and economic activity related to the sharing economy.

\section{References}

Airbnb (2017). Retrieved from: https://www.businessinsider.com/airbnb-growth-in-london-number-of-guests-surpass-4-million-20171?IR=T.

Albino, V., Berardi, U., Dangelico, R.M. (2018). Smart cities: definitions, dimensions, and performance. Journal of Urban Technology, 22 (1), 3-21.

Botsman, R., Rogers, R. (2010). What's Mine Is Yours, The Rise of Collaborative Consumption. New York: HarperCollins. 
Botsman, R. (2015). Defining The sharing economy: What Is Collaborative Consumption - And What Isn't? Fast Company. Retrieved from: https://www.fastcompany.com/3046119/defining-the-sharing-economy-what-is-collaborative-consumption-and-what-isnt.

Chase, R. (2015). How People and Platforms Are Inventing the Collaborative Economy and Reinventing Capitalism. New York: Public Affairs.

Chojnicki, Z. (1989). Koncepcja terytorialnego systemu społecznego. Przegląd Geograficzny, 60 (3), 491-510.

Cohen, B. (2015). The 3 Generations of Smart Cities. Retrieved from: https://www.fastcompany.com/3047795/the-3-generationsof-smart-cities.

Frenken, K., Schor, J. (2017). Putting the sharing economy into perspective. Environmental Innovation and Societal Transitions, 23, 3-10.

Ganapatia, S., Reddickb, C.G. (2018). Prospects and challenges of sharing economy for the public sector. Government Information Quarterly, 35, 77-87.

Gansky, L. (2010). The Mesh: Why the Future of Business Is Sharing. The Sharing Economy. London: Portfolio Penguin. Retrieved from: https://informationdj.files.wordpress.com/2012/01/future-of-business-is-lisa-gansky.pdf.

Gavaldà, J., Ribera, R. (2012). Barcelona 5.0: From Knowledge to Smartness? Working Paper Series. WP12-002. Barcelona, Spain: Universitat Oberta de Catalunya. Retrieved from: http://in3-working-paper-series.uoc.edu/in3/en/index.php/in3-working-paperseries/article/download/1590/1590-4557-1-PB.pdf.

Martin, C.J., Upham, P., Budd, L. (2015). Commercial orientation in grassroots social innovation: insights from the sharing economy. Ecological Economics, 118, 240-251.

McLaren, D., Agyeman, J. (2015). Sharing Cities: A Case for Truly Smart and Sustainable Cities. MIT Press.

Mierzejewska, L. (2015). Zrównoważony rozwój miasta - wybrane sposoby pojmowania, koncepcje i modele. Problemy rozwoju miast. Kwartalnik Naukowy Instytutu Rozwoju Miast, XII, 5-11.

Owyang, J. (2014). Framework: Collaborative Economy Honeycomb. Retrieved from: www.web-strategist.com/blog/2014/05/05/ framework-collaborative-economy-honeycomb-osfest14.

Owyang, J. (2019). Roadmap: Five Phases of Digital Eras. Retrieved from: www.web-strategist.com/blog.

PWC (2015). The sharing economy. Consumer Intelligence Series. Retrieved from: https://www.pwc.fr/fr/assets/files/pdf/2015/05/ pwc_etude_sharing_economy.pdf.

Ramaprasad, A., Sánchez-Ortiz, A., Syn, T. (2017). Unified Definition of a Smart City. IFIP International Federation for Information Processing. In: Electronic Government (pp. 13-14). Springer International Publishing AG.

Selloni, D. (2017). CoDesign for Public-Interest Services. Research for Development. Springer International Publishing AG.

Smart cities Ranking of European medium-sized cities (2007). Final report Edited by the Centre of Regional Science. Vienna UT, 11-12.

U.S. Department of Commerce, Economics and Statistics Administration, Office of the Chief Economist (ESA) (2016). Digital matching firms: A new definition in the "sharing economy": space. ESA Issue Brief, 1-16. Retrieved from: www.esa.gov/sites/default/files/ digital-matching-firms-new-definition-sharing-economy-space.pdf.

Cite this anticle aS: Rudewicz, J. (2018). The role of services based on the sharing economy model in the Smart City 3.0 concept. European Journal of Service Management, 4 (28/2), 387-394. DOI: 10.18276/ejsm.2018.28/2-46. 